\title{
Grid balancing with a large-scale electrolyser providing primary reserve
}

ISSN 1752-1416

Received on 28th April 2020

Revised 27th August 2020

Accepted on 11th September 2020

E-First on 29th November 2020

doi: 10.1049/iet-rpg.2020.0453

www.ietdl.org

\author{
Arash E. Samani ${ }^{1,2}$ 凶, Anna D'Amicis ${ }^{3}$, Jeroen D.M. De Kooning ${ }^{1,4}$, Dimitar Bozalakov ${ }^{1,2}$, Paolo Silva ${ }^{5}$, \\ Lieven Vandevelde ${ }^{1,2}$ \\ ${ }^{1}$ Department of Electromechanical, Systems and Metal Engineering (ESME), Ghent University, Tech Lane Ghent Science Park - Campus A, \\ Technologiepark Zwijnaarde 131, B-9052 Ghent, Belgium \\ ${ }^{2}$ Corelab EEDT-DC, Ghent, Belgium \\ ${ }^{3} A D N E O M$, Brussels, Belgium \\ ${ }^{4}$ Corelab EEDT-MP, Ghent, Belgium \\ ${ }^{5}$ Department of Energy, Politecnico di Milano, Milan, Italy \\ E-mail: ebnealisamani.arash@ugent.be
}

\begin{abstract}
As the share of renewable energy sources increases, the grid frequency becomes more unstable. Therefore, grid balancing services will become more important in the future. Dedicated devices can be installed close to the point where offshore wind farms are connected to the transmission grid on land. There, they can be used to attenuate power variations, reduce congestion and offer grid balancing. The provision of these ancillary services can create considerable additional economic revenue. In this study, the provision of the primary reserve by means of a large hydrogen electrolyser of $25 \mathrm{MW}$ is investigated for the specific case of the Belgian transmission system. The revenue of the provision of the frequency containment reserve (FCR) is analysed on a techno-economic model, including capital costs, operational costs, the revenue of the generated hydrogen and oxygen products and the ancillary service income. The revenue depends strongly on the contracted power band. Therefore, it is optimised to yield maximum revenue. The results show that providing FCR creates considerable additional revenue. Therefore, a large electrolyser can be a good candidate to buffer excess renewable energy into green gas while simultaneously providing the grid support.
\end{abstract}

\section{Nomenclature}

$\Delta P \quad$ power reserve

$P_{\mathrm{e}} \quad$ electric power consumption

$K \quad$ power consumption factor

$C_{\mathrm{el}} \quad$ electricity price

$P_{0} \quad$ baseload

$\mathrm{CF}$ annual cash flow

$t \quad$ time step

$\mathrm{H}_{2 \mathrm{v}} \quad$ hydrogen value

$\mathrm{H}_{2 \mathrm{p}} \quad$ produced hydrogen

$P_{\mathrm{r}} \quad$ power ratio

$\alpha \quad$ baseload power as a percentage of the maximum capacity

$P_{\max }$ maximum capacity

$f \quad$ grid frequency

$k \quad$ power-frequency characteristic

min technical minimum of operating power

$\Delta f \quad$ frequency deviation

$\lambda_{\mathrm{fcr}} \quad$ value of the FCR

$\beta \quad$ availability of the electrolyser

$P_{\text {min }} \quad$ minimum power

$e_{t} \quad$ output voltage

$E_{0} \quad$ electrode potential difference

$R_{\mathrm{m}} \quad$ ohmic losses in the membrane

$Z_{\text {el }} \quad$ total impedance

$Z_{\mathrm{a}} \quad$ anode impedance

$Z_{\text {c }} \quad$ cathode impedance

$Z_{\text {wbg }} \quad$ Warburg impedance

NPV net present value

$i \quad$ discount rate

$N \quad$ lifetime

IRR internal rate of return

FCR frequency containment reserve
$I_{\text {in }} \quad$ input current

$E_{\text {cell }} \quad$ PEM cell voltage

$\mathrm{Pa}$ output pressure

$T$ temperature

$E_{\text {th }} \quad$ thermoneutral voltage

$E_{\text {ac, a }}$ activation voltage of the anode

$E_{\mathrm{ac}, \mathrm{c}}$ activation voltage of the cathode

$E_{\mathrm{ohm}} \quad$ ohmic voltage drop

\section{Introduction}

The electric power industry is changing continuously due to growing diversity in the energy mix. This is mainly caused by the increasing share of renewable energy sources. Global warming and climate change are the main reasons for a rapid global transition towards renewable energy generation. Furthermore, fossil fuel reserves are being depleted progressively while the demand for energy keeps increasing. Also, the levellised cost of energy (LCOE) of renewables has decreased drastically to a level where it is cheaper than classical energy sources, e.g. natural gas or nuclear energy. Clearly, a more diverse energy mix is needed, which requires a change in the structure and operation of the conventional power system.

Besides the positive aspects of increasing the share of renewables in the energy mix, the technical feasibility of integrating variable renewable sources should be considered. Due to the intermittent nature of these sources, they bring more fluctuations and uncertainty into the grid and complicate its operational management. However, as wind and solar power are the fastest-growing sources of electricity, their effects must be taken into account $[1,2]$. For example, the inertial response of the grid on power imbalances is determined by all rotating masses of the turbo-generators in the system. However, renewable power sources such as wind turbines and photovoltaics do not possess 
directly coupled rotating inertia, which reduces the robustness and stability of the power system [3-5].

Different solutions such as energy storage systems (ESSs), demand-side response (DSR), and curtailment of variable renewable energy sources have been suggested to manage the energy flows and increase the flexibility of the grid [6-9]. ESS with a certain degree of flexibility can be used to charge, hold and discharge the electricity according to the condition of the grid. Storage technologies with different characteristics have been developed to provide electrical storage for a wide range of power, i.e. pumped hydroelectric storage (PHS), batteries, flywheels and hydrogen technologies. PHS has a long discharge time and a large power storage capacity is counted as utility-scale energy storage. Although pumped hydroelectric energy storage is well suited for bulk power management, specific geographic conditions are required, i.e. geologic and hydrologic constraints. Batteries with a fast response have the potential advantage to be used for frequency regulation [10]. However, this technology, with its low energy density (energy per unit volume), is not able to store a large amount of energy. Therefore, for a grid-scale battery system, a large number of cells are required to store the excess electricity production. Flywheel ESSs can provide immediate active power to support the grid. Their main advantage is the fast response time, which makes them suitable for frequency regulation. However, compared to other storage systems, they have a shorter discharge time and power storage, i.e. up to $1 \mathrm{MW}$ for less than an hour. Hydrogen storage systems have higher performance in terms of energy storage, i.e. $1 \mathrm{GWh}$ up to $1 \mathrm{TWh}$, and a discharge time compared to the aforementioned storage systems. Therefore, hydrogen, as an energy carrier, can be one of the possible options for voltage and frequency stabilisation [11-13]. Despite the advantages of hydrogen storage systems, the direct conversion of electrical energy to hydrogen is not economically viable due to the high electrolyser costs and relatively low hydrogen price. Nevertheless, hydrogen storage systems can play a fundamental role where a high amount of renewable energy is available, and more grid support is required.

Studies show that electricity-based hydrogen plays a key role in reducing greenhouse gas emissions in the future of the European Union. Hydrogen, as a clean vector, is used in fuel cell-based electric vehicles which leads to a de-carbonisation of the transport sector. Moreover, hydrogen can contribute in the energy market as a provider of flexibility $[14,15]$. The results of a recent technoeconomic assessment of the hydrogen production mix for road transport explains that the electrolyser could act as a key technology to fulfil its hydrogen demand in the medium and long term [14]. It is found in [15] that the most important technoeconomic properties of electrolysers are their ability to operate flexibly and the efficient conversion of electricity into hydrogen. These studies show that electrolysers have a positive effect on frequency stability, as electrolysers are able to respond faster to frequency deviations than conventional generators [16].

Large-scale electrolysers are an energy-intensive technology that can be operated to support the grid by regulating the input power based on the grid's condition, i.e. to deliver ancillary services. Therefore, additional revenue can be generated by participating in ancillary markets. In the recent research conducted by Mohanpurkar et al., the performance of electrolyser systems in providing grid support was investigated. The dynamic response of an electrolyser participating in demand response, local voltage support, and frequency support was tested by utilising the fast response of the electrolyser, i.e. subsecond level. The results verified that electrolysers can be utilised as controllable loads without negatively impacting their life. However, the economic analysis and exact economic benefits due to participating in the demand side response were not covered in [17]. Based on the findings of Allidières et al., polymer electrolyte membrane (PEM) water electrolysis stacks/plants represent sufficient flexibility and reactivity to provide primary and secondary power reserves. However, it was concluded that the existing technology requires further developments to reduce efficiency losses and degraded power responses in the conditions of interest for grid services [18]. Matute et al. [19] performed a techno-economic analysis of multi-
MW electrolysis plants designed to provide grid services while producing hydrogen for different end uses. The results showed that combining multi-MW electrolysers with the provision of secondary reserve in Spain is a valid option to obtain cost-competitive hydrogen for different applications. However, a sufficient hydrogen demand is required for the profitability of a hydrogen refuelling station network [19].

In this paper, a techno-economic analysis is performed of a 25 MW PEM electrolyser installation in Belgium, planned to provide grid services while injecting hydrogen into the natural gas pipeline. Different electrolyser operational strategies are investigated to find the optimal method of running the electrolyser, which maximises the economic return. Later, an electrolyser system, i.e. cell stack and controller, is developed to examine the controllability and reactivity of the electrolyser operating with the proposed strategy. A numerical model is developed in Matlab to assess the economic benefits of running a large-scale electrolyser with two different strategies. In the first strategy, the power consumption is varied based on the electricity price variations on the Epex Spot market. As price variations are correlated with the balance of the grid through the supply and demand principle, this operating strategy is a form of grid balancing. In the second strategy, the economic return is maximised by providing frequency containment reserve (FCR) as an ancillary service. Once the optimal operating strategy is determined, an electrochemical model of the electrolyser is developed to test the system response under the most extreme variation in the grid frequency. In this paper, we propose an optimal strategy for operating a large-scale electrolyser in Belgium. The main contributions are:

- Maximising the economic efficiency of a large-scale electrolyser installation.

- Optimal contribution of an electrolyser in the Belgian ancillary service market.

- Technical validation of the proposed strategy for providing symmetric $100 \mathrm{mHz}$ frequency containment reserve.

- Monitoring the response of the dynamic model to the maximum frequency variation in the year 2017.

- Suggesting a generic techno-economic model which can offer useful and incentive information for the hydrogen sector to improve the economic viability of electrolysers by providing grid balancing services.

This paper is organised as follows: Section 2 describes the business case and methodology. The optimisation of the electrolysers power consumption is described in Section 2.1. Section 2.2 explains the strategy of providing ancillary services to the grid. The electrolyser degradation and modelling are discussed in Section 2.3. The optimisation and simulation results of each strategy are presented in Sections 3.1 and 3.2, respectively. The PEM electrolysers dynamic response to the grids condition is discussed in Section 3.3.

\section{Methodology}

Since hydrogen production through electrolysis is an energyintensive process, the electricity price is of vital importance to the economic viability of the electrolyser. As the first business case, the electrolyser is operated to follow the variations in the electricity price. As mentioned before, these variations are linked to the grid balance through the supply and demand principle. Hydrogen storage is not foreseen in the model, assuming that all the produced hydrogen can be injected into the conventional natural gas grid as long as a limit of $2 \%$ volume hydrogen is not exceeded. This limit is imposed to avoid exceeding flame temperature limits in natural gas consumers. To inject the hydrogen into the existing natural gas pipeline, it must be compressed from 30 to 70 bar. It is assumed that the compression stages are not costly in comparison to the electrolysis. Therefore, the compression station costs are not included. However, for high-pressure applications such as mobility (pressure level up to 700 bar), the compression cost is not negligible. Injecting hydrogen in the natural gas grid reduces the $\mathrm{CO}_{2}$ emission with $202 \mathrm{~kg} / \mathrm{MWh}\left(39 \mathrm{kWh}(\mathrm{HHV}) / \mathrm{kg}_{\mathrm{H}_{2}}\right)$ [20]. 
However, the avoided emission of $\mathrm{CO}_{2}$ does not generate substantial revenue for the hydrogen supplier. Table 1 gives an overview of the assumptions and the main parameters of the electrolyser.

The second business case aims to analyse the possible profitability of using the electrolyser to provide DSR services. Ancillary services are essential to support the power grid stability in unbalanced situations. Moreover, participating in the ancillary market brings additional economic revenue. The ancillary services can be provided by regulating the power offtake of the electrolyser according to the grid frequency. In this economic model, the power consumption profile of the electrolyser is varied based on the frequency variation of the Belgian grid in 2017, operated by the transmission system operator Elia.

The additional economic revenue of the provision of each FCR product type (two symmetrical and two asymmetrical products) will be investigated. Symmetrical FCR products are delivered within a frequency deviation of 100 or $200 \mathrm{mHz}$ from the nominal $50 \mathrm{~Hz}$ upward or downward. Asymmetrical FCR products are provided if the frequency deviates more than $100 \mathrm{mHz}$ from nominal, either upward or downward. The power reserve offered by the electrolyser is assumed to be constant for the whole year, though the tendering process is evolving to a shorter period in the future.

The power response of alkaline and PEM electrolysers to frequency variations of the grid can be easily modulated [17]. The response time from pressurised standby to a full-load operating condition is $<3 \mathrm{~s}$. A hot-start is even faster, i.e. $<1 \mathrm{~s}$. However, it is not recommended to frequently switch the electrolysers entirely on and off in stand-alone systems, from a system frequency control perspective [21]. Therefore, to provide an adequate response to the grid frequency variation and to fulfil the technical specifications, the electrolyser is supposed to be continuously operated in a variable way to avoid the start-up and shut-down time required to purge the nitrogen. Thus, a minimum operating capacity of $10 \%$ $(2.5 \mathrm{MW})$ is considered.

The average prices of all primary reserve products in 2017 are given in Table 2 . The hourly electricity price in the model is equal to the Epex Spot electricity price in 2017 with an average price of $44.6 € / \mathrm{MWh}$. The same assumptions as the first business case are considered with a difference that the ancillary service is included in the optimisation algorithm as an end product. Therefore, the algorithm optimises the objective function of producing hydrogen and providing ancillary services as the end products, based on the annual average Epex Spot electricity price. The optimisation aims to find the baseload power and power reserve at which the maximum revenue is generated.

The investment profitability of the electrolyser for the lifespan of 20 years is calculated, taking into account both the operational and investment costs. The cash flow (CF) is kept identical for each year based on the assumption that both the hydrogen and electricity price will increase by the same amount. According to Thomas et al. [20], the hydrogen value for on-site production will reach $2.72 € / \mathrm{kg}$ in 2030 and $3.59 € / \mathrm{kg}$ in 2050 , with an average yearly increase of $2 \%$. As the electricity prices are also expected to rise in the near future, an annual increase of $2 \%$ is assumed. However, by scheduling the power input according to the electricity price, the power consumption decreases, and the influence of the electricity price evolution is cancelled out. The electrolytic cells wear out over time, and a replacement is required after 10 years (half of the lifetime) with a cost of $50 \%$ of the initial investment. This replacement cost is included in the CF of the tenth year, and it is weighed with the discounting factor. To analyse the economic feasibility of operating the electrolyser with the first strategy, the net present value (NPV) is calculated as:

$$
\mathrm{NPV}=\sum_{k=1}^{N} \frac{\mathrm{CF}(a)}{(1+i)^{k}}
$$

where $a$ is the year, $\operatorname{CF}(a)$ is the cash flow in the year $a, i$ is the discount rate, and $N$ is the lifetime. A discount rate of $2 \%$ is considered.

\subsection{Power input optimisation}

In the first strategy, the power input of the electrolyser is dynamically modulated to follow the electricity price. No ancillary service provision is considered. The electric power consumption $P_{\mathrm{e}}$ is regulated as a linear function of the electricity price:

$$
P_{\mathrm{e}}=P_{0}-K C_{\mathrm{el}}
$$

where $K$ is a constant control factor that determines how strongly the power consumption reacts to price variations. The hourly electricity price is represented by the variable $C_{\mathrm{el}} . P_{0}$ is the baseload power which can be set between a minimum of $2.5 \mathrm{MW}$, to avoid start-up time, and a maximum of $25 \mathrm{MW}$. An optimisation algorithm maximises the annual CF of the system with an objective function in which electricity expenditure and hydrogen sale are considered as the main cost and revenue drivers, respectively. The objective function of the algorithm is defined as follows:

$$
\mathrm{CF}=\sum_{t=1}^{T}\left(\mathrm{H}_{2 \mathrm{v}} \mathrm{H}_{2 \mathrm{p}}^{t}-P_{\mathrm{e}}^{t} C_{\mathrm{el}}^{t}\right) \Delta T
$$

where electricity consumption $P_{\mathrm{e}}$ specified at each time step $t$, (where $t=1,2, \ldots, 8760 \mathrm{~h}$ ). The amount of hydrogen produced varies on an hourly basis, as the electricity price also varies hourby-hour. The value of hydrogen $\mathrm{H}_{2 \mathrm{v}}$ is a constant, given in Table 1 . The produced hydrogen in the function of the operating power is calculated by (4), considering the partial load efficiency of the electrolyser. The equation is obtained based on experimental data provided by Hydrogenics, a manufacturer of hydrogen generation and fuel cells

$$
\mathrm{H}_{2_{\mathrm{p}}}=\left(-5.9 \cdot P_{\mathrm{r}}^{2}+5.07 \cdot P_{\mathrm{r}}+20.17\right) \cdot P_{\mathrm{e}}
$$

where

$$
P_{\mathrm{r}}=\frac{P_{\mathrm{e}}}{P_{\max }}
$$

Fig. 1 shows the annual CF of the electrolyser as a function of the baseload $P_{0}$ and the control parameter $K$. The annual CF reaches its maximum at $K=0.29$ and $P_{0}=25 \mathrm{MW}$ (maximum baseload). Operating the electrolyser at these optimum values generates the maximum revenue for the system, considering the hydrogen production and the electricity expenditure as the main parameters in the cost function.

Operating the electrolyser at its maximum capacity with $K=$ 0.29 makes the CF mostly positive, giving the possibility to follow the electricity price with considerable hydrogen production.

\subsection{Providing primary reserve}

2.2.1 Symmetric 100 and $200 \mathrm{mHz}$ FCR product: To provide symmetrical 100 and $200 \mathrm{mHz}$ FCR products, the electrolyser is never operated at the maximum or minimum capacity on an average, to keep the power reserve available for the positive and negative variations of the grid frequency. Therefore, the baseload power is set between 15 and $95 \%$ of the maximum capacity (3.75$23.75 \mathrm{MW}$ ). In these strategies, the power input responds linearly and proportionally to the frequency variations of the grid. According to the grid operator regulations in Belgium, a deadband of $10 \mathrm{mHz}(50 \mathrm{~Hz} \pm 10 \mathrm{mHz})$ is considered, in which the primary control is not allowed to react, and the electrolyser operates at its baseload power. The equation used to guarantee such behaviour is

$$
P_{\mathrm{e}}= \begin{cases}\alpha P_{\max } & -0.01 \leq \Delta f \leq 0.01 \\ \alpha P_{\max }+k \Delta f & \text { otherwise }\end{cases}
$$

where $\alpha$ is the baseload power as a percentage of the maximum capacity $P_{\max }$. This is the variable that is optimised in the algorithm. The frequency of the grid is represented by $f$. The parameter $\Delta f$ is 
Table $125 \mathrm{MW}$ electrolyser parameters and assumptions

\begin{tabular}{lc}
\hline $25 \mathrm{MW}$ PEM electrolyser & \\
\hline capital expenditure (CAPEX) & $1000 € / \mathrm{kW}[20]$ \\
operational cost & $1 \%$ of capital cost \\
nominal $\mathrm{H}_{2}$ output & $5000 \mathrm{Nm}^{3} / \mathrm{h}$ \\
lifetime & 20 years \\
availability & $98 \%$ \\
cell stack lifetime & $80,000 \mathrm{~h}$ \\
operating hours & $8760 \mathrm{~h} / \mathrm{year}$ \\
substitution cell & $50 \%$ of capital cost \\
output pressure & $30 \mathrm{bar}$ \\
connection cost to the power grid & $500,000 €$ \\
connection cost to the gas grid & $2,250,000 €$ \\
value of generated hydrogen & $2.2 € / \mathrm{kg}[20]$ \\
value of generated oxygen & $24.5 € /$ ton $[20]$ \\
\hline
\end{tabular}

Table 2 Annual average price of contracted primary reserves

\begin{tabular}{lc}
\hline FCR product & Price, $€ / \mathrm{MW} / \mathrm{h}$ \\
\hline symmetric $100 \mathrm{mHz}$ & 33 \\
symmetric $200 \mathrm{mHz}$ & 15 \\
ssymmetrical & 4 \\
\hline
\end{tabular}
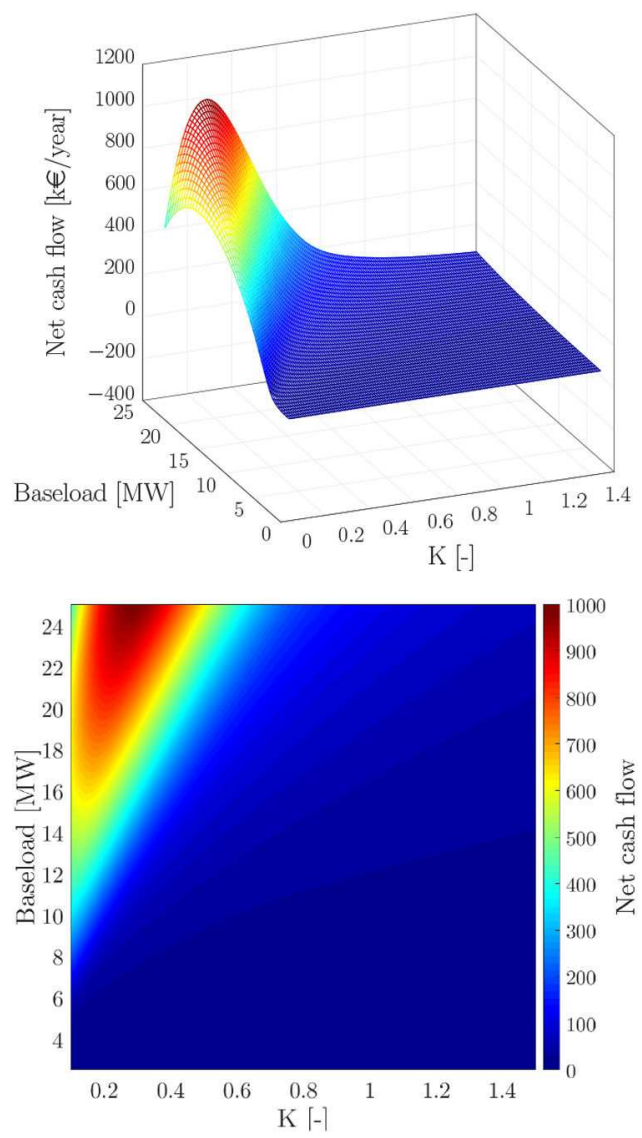

Fig. 1 Net $C F$ as a function of $K$ and $P_{0}$

the frequency deviation from $50 \mathrm{~Hz}(\Delta f=f-50 \mathrm{~Hz}) . k$ is the power-frequency characteristic of the electrolyser, defined as

$$
k=\frac{\Delta P}{\Delta f} .
$$

The symmetric $\mathrm{mHz}$ FCR product covers the frequency deviation $\Delta f$ up to $100 \mathrm{mHz}$. The symmetrical product with respect to the nominal frequency gives an equal chance for downward and upward requests to stabilise the frequency. To provide a symmetrical $200 \mathrm{mHz}$ product, the system reacts to a frequency deviation of $200 \mathrm{mHz}$ from the nominal value. The power input reacts linearly to the frequency variation with a less steep slope compared to the $100 \mathrm{mHz}$ product, because of the less restrictive activation range $(48.8-50.2 \mathrm{~Hz})$. The equation that expresses the power reserve is as follows:

$$
\Delta P= \begin{cases}P_{0}-P_{\min }, & \alpha \leq \frac{1-\min }{2}+\min \\ P_{\max }-P_{0}, & \alpha>\frac{1-\min }{2}+\min \end{cases}
$$

The annual CF is calculated as

$$
\mathrm{CF}=\sum_{t=1}^{T}\left(\mathrm{H}_{2_{\mathrm{v}}} \mathrm{H}_{2 \mathrm{p}}^{t}+\Delta P^{t} \lambda_{\mathrm{fcr}} \beta-P_{\mathrm{e}}^{t} C_{\mathrm{el}}\right) \Delta T
$$

where $\lambda_{\text {fcr }}$ is the value of the FCR product, $\mathrm{H}_{2}^{v}$ is the value of hydrogen $(2.2 € / \mathrm{kg}), t=1,2, \ldots, 8760 \mathrm{~h}$, and $\beta$ is the availability of the electrolyser, i.e. $98 \% . \mathrm{H}_{2 \mathrm{p}}$ is the produced hydrogen which changes linearly with the power input indicated by $P_{\mathrm{e}}$, and can be calculated using (4).

2.2.2 Asymmetrical FCR downwards: To provide the asymmetrical product FCR downwards, the system reacts to frequency deviations above $50.1 \mathrm{~Hz}$. Therefore, if the grid frequency is above $50.1 \mathrm{~Hz}$, the power input of the electrolyser follows the frequency as:

$$
P_{\mathrm{e}}= \begin{cases}\alpha P_{\max }+k \Delta f & \delta>0 \\ \alpha P_{\max } & \text { otherwise }\end{cases}
$$

where $\Delta f=f-50.1 \mathrm{~Hz}$, and $k$ is the power frequency characteristic of the electrolyser for a frequency deviation of 0.2 Hz. To keep the power reserve available, the electrolyser cannot be operated at its maximum capacity. Therefore, the baseload varies between a technical minimum of 10 and $95 \%$. The power reserve is given by

$$
\Delta P=P_{\max }-P_{0} .
$$

2.2.3 Asymmetrical FCR upwards: In this strategy, the electrolyser reacts to the grid frequency when the frequency is below $49.9 \mathrm{~Hz}$. The power input varies as a function of frequency according to

$$
P_{\mathrm{e}}= \begin{cases}\alpha P_{\max }+k \Delta f & \Delta f<0 \\ \alpha P_{\max } & \text { otherwise }\end{cases}
$$

where $k$ is the power frequency characteristic of the electrolyser for a frequency deviation of $0.2 \mathrm{~Hz}$, and $\Delta f=f-49.9 \mathrm{~Hz}$. The baseload varies between 15 and $100 \%$. The power reserve is calculated as

$$
\Delta P=P_{0}-P_{\min }
$$

\subsection{Electrolyser model}

When electrolysers are used as variable loads, both their static and dynamic performance must be considered. During the exploitation of the electrolyser, its static behaviour can vary depending on the accumulated operating hours, which is known as stack degradation. As will be shown, the dynamic behaviour of the PEM stack will be included in the model.

2.3.1 PEM stack degradation: When current is flowing through a PEM cell, a voltage drop is created. According to the authors in $[22,23]$ this voltage drop is composed of several components. In addition, this voltage is dependent on the stack output pressure and 

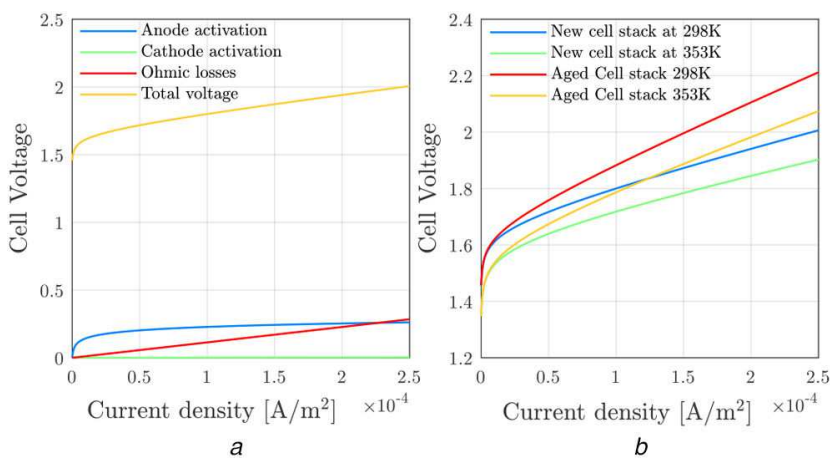

Fig. 2 PEM stack degradation impact

(a) Different PEM cell voltages as a function of the current density, (b) V-I characteristics of a degraded PEM cell (after $80,000 \mathrm{~h}$ of operation) at $353 \mathrm{~K}\left(80^{\circ} \mathrm{C}\right.$ ) and $298 \mathrm{~K}\left(25^{\circ} \mathrm{C}\right)$
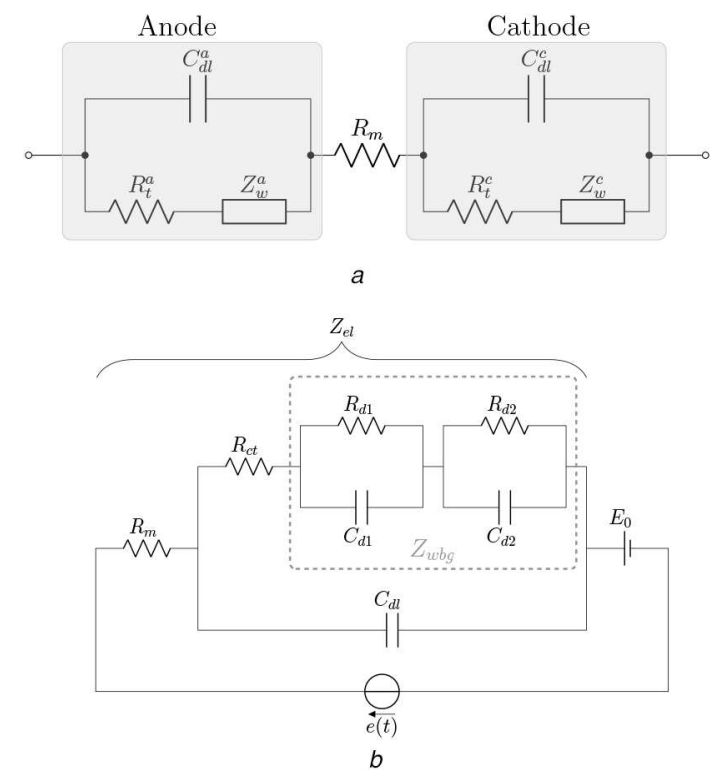

Fig. 3 PEM stack model

(a) Electrical model, (b) Electrochemical model with Randles-Warburg cell

Table 3 Randles-Warburg model parameters

\begin{tabular}{ccccccc}
\hline$R_{\mathrm{ct}}, \Omega$ & $C_{\mathrm{dl}}, \mathrm{F}$ & $R_{d 1}, \Omega$ & $C_{d 1}, \mathrm{~F}$ & $R_{\mathrm{m}}, \Omega$ & $R_{d 2}, \Omega$ & $C_{d 2}, \mathrm{~F}$ \\
\hline 0.331 & 0.545 & 0.013 & 1080 & 0.381 & 0.121 & 14,400 \\
\hline
\end{tabular}

temperature [24]. The mathematical expression for the cell voltage is given as follows:

$$
E_{\text {cell }}(\mathrm{Pa}, T)=E_{\mathrm{th}}+E_{\mathrm{ac}, \mathrm{a}}+E_{\mathrm{ac}, \mathrm{c}}+E_{\mathrm{ohm}}
$$

where $E_{\text {cell }}$ is the PEM cell voltage, $\mathrm{Pa}$ is the output pressure, $T$ is the temperature, $E_{\mathrm{th}}$ is the thermoneutral voltage, $E_{\mathrm{ac}, \mathrm{a}}$ is the activation voltage of the anode, $E_{\mathrm{ac}, \mathrm{c}}$ is the activation voltage of the cathode and $E_{\mathrm{ohm}}$ is the ohmic voltage drop.

In [22-27], the necessary data to fill in (14) and the results are presented in Fig. $2 a$. These results are obtained at $25^{\circ} \mathrm{C}, 30$ bar pressure and a current density between 0 and $2.5 \mathrm{~A} / \mathrm{mm}^{2}$. The major contributor to the PEM voltage is the thermoneutral voltage, which gives an offset of $1.483 \mathrm{~V}$. In practice, a typical value used for the current density is $1 \mathrm{~A} / \mathrm{mm}^{2}$. At this point, the next more dominant component is the anode activation voltage and finally the ohmic voltage drop. By using these parameters, the resultant voltage drop is obtained to be $E_{\text {cell }}(\mathrm{Pa}, T)=1.8 \mathrm{~V}$.

In this paper, it is assumed that the lifespan of the PEM stack is $80,000 \mathrm{~h}$ (see Table 1). In the literature, it was found that the major contributor for the stack degradation is the increased ohmic resistance of the electrodes and membrane. A typical degradation rate of the stack is considered to be about $1 \mathrm{mV}$ per cell for $1000 \mathrm{~h}$ operating at full load [28]. Therefore, the total cell voltage increase is $80 \mathrm{mV}$, i.e. $1.880 \mathrm{~V}$ after $80,000 \mathrm{~h}$ of operation. Fig. $2 b$ shows the curves of new and degraded cells. In this particular case, the degraded cell has $82.7 \%$ more ohmic resistance compared to a new cell. If a constant cell voltage is applied at the cell terminals, then the current density drops from $1^{2}$ to $0.7 \mathrm{~A} / \mathrm{mm}^{2}$, which will result in a decreased hydrogen production. However, these results are obtained at $25^{\circ} \mathrm{C}(298 \mathrm{~K})$. Usually, the PEM stack temperature is higher than that, as it reaches $80^{\circ} \mathrm{C}(353 \mathrm{~K})$. Fig. $2 b$ also shows the curves of new and degraded cells at $80^{\circ} \mathrm{C}$. It can be seen that the degraded cell voltage decreases at higher temperature, and at $1 \mathrm{~A} / \mathrm{mm}^{2}$ it is close to a new cell voltage. The voltage of the new cell decreases even further down to $1.72 \mathrm{~V}$ at high temperatures for the same current density.

The conducted analysis shows that the cell degradation does not have a severe impact on the PEM stack consumption and power supply performance. Indeed, with a new stack and high temperatures, the PEM power will be slightly lower and gradually increasing with the degradation. Nevertheless, the maximum power at a new stack is known, and it can be used as a contracted power for ancillary services. With the degradation of the stack, the power will increase, but the contracted power will be intact, and the electrolyser will continue to provide FCR as expected. From (14), it is evident that the cell voltage is dependent on pressure and temperature. The additional 'Balance of Plant' (BoP) components in the system, i.e. chillers, compressors etc. are assumed to regulate the pressure and PEM stack temperature such that the total power can be controlled.

2.3.2 Dynamic model of the PEM stack: The electrochemical model of the PEM electrolyser can be described with Randles circuits connected in series. The electrolyser impedance can be calculated from the difference of the standard electrode potential $E_{0}$ and the measured output voltage $e_{t}$, which is given by (15):

$$
Z_{\mathrm{el}}=\frac{V_{\mathrm{el}}}{I_{\mathrm{in}}}
$$

The voltage drop across the electrolyser is the sum of the overvoltages of the anode, the cathode and the membrane. Therefore, the equivalent impedance of a PEM is composed of the cathode and anode impedance in series with the ohmic losses in the membrane $R_{\mathrm{m}}$ [29]. The total impedance $Z_{\mathrm{el}}$ of the PEM cell is then given by

$$
Z_{\mathrm{el}}=Z_{\mathrm{a}}+R_{\mathrm{m}}+Z_{\mathrm{c}}
$$

As illustrated in Fig. $3 a$, the impedances of anode and cathode are composed of the double-layer capacitance, the resistance of the charge transfer to the electrode, and the Warburg impedance $\left(C_{\mathrm{dl}} \|\left[R_{\mathrm{t}}+Z_{\mathrm{w}}\right]\right)[30,31]$. The electrical model can be simplified to the Randles-Warburg (RW) model, in which The RW cell represents the PEM impedance $Z_{\mathrm{el}}$ [31-33]. The equivalent electrical circuit of the RW can be used to model the impedance response of electrochemical systems such as a galvanic cell or an electrolytic cell [34]. The electrochemical model of the PEM electrolyser based on the RW cell is illustrated in Fig. $3 b$. The equation of the Warburg impedance $Z_{\mathrm{wbg}}$ in the Laplace domain is given by

$$
Z_{\mathrm{wbg}}(s)=\frac{R_{d 1}}{1+R_{d 1} C_{d 1} s}+\frac{R_{d 2}}{1+R_{d 2} C_{d 2} s}
$$

The parameter values of the RW model are estimated based on the physical characteristics of the system. The parameters in [35] are upscaled with different factors to give the desired impedance behaviour of the $25 \mathrm{MW}$ PEM electrolyser. The values of these parameters are given in Table 3.

Up to this point the dynamic behaviour was presented under the assumption of a new stack. Nevertheless, with the degraded stack, 


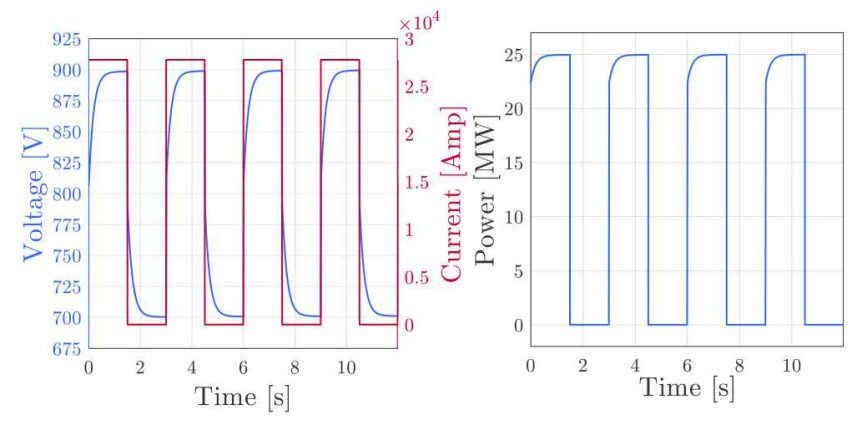

Fig. 4 Dynamic response of the PEM stack to the ideal current source

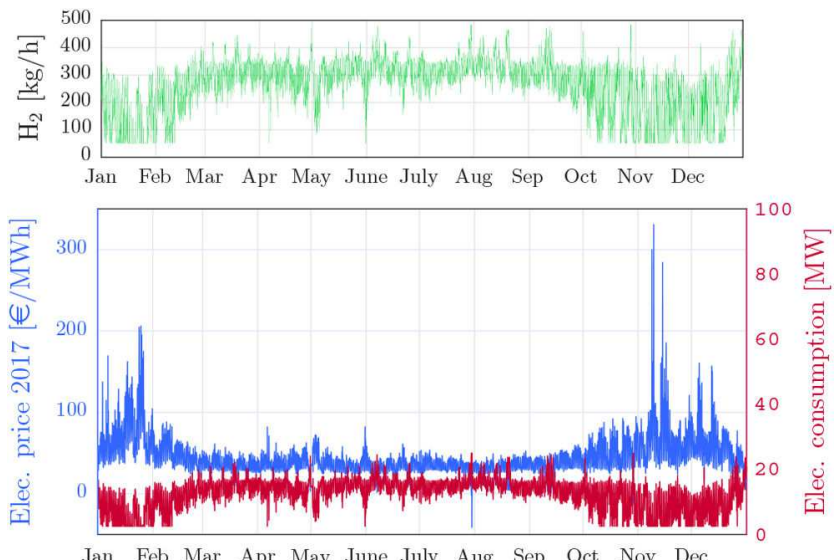

Fig. 5 Electrolyser power consumption in 1 year
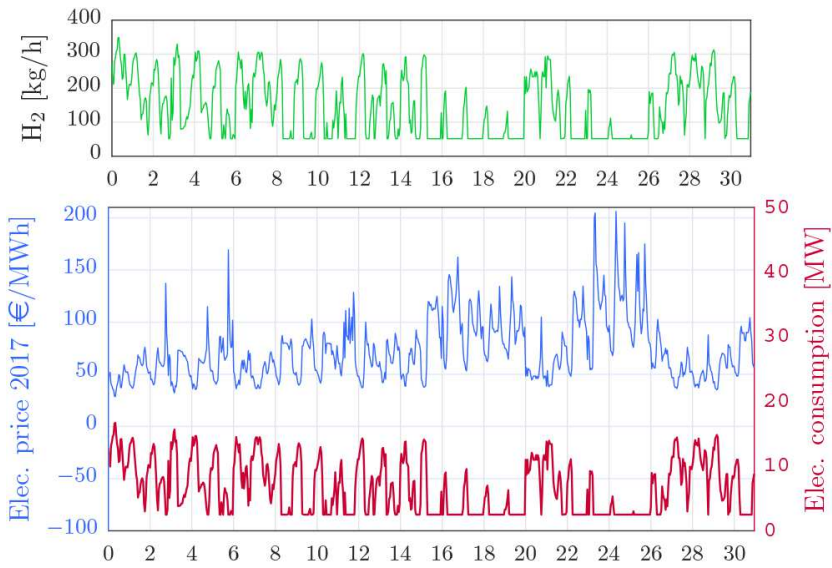

Fig. 6 Electrolyser power input in first day of the year

the ohmic resistance increases, while the capacitance remains the same. This will increase the time constant of the PEM stack. However, the change will not be greater than the time constant of the BoP equipment. Therefore, even if the stack is degraded, the whole system will be able to provide a fast response which is suitable for ancillary services provision.

The dynamic performance of the model based on the approximated parameters is monitored by applying an ideal current source, which is shown in Fig. 4. The PEM model reacts to the current changes, and the power signal settles down within one second at maximum, while the PEM voltage reaches $0.9 \mathrm{kV}$ at the rated power.

\section{Optimisation and simulation results}

\subsection{Power input optimisation}

Fig. 5 shows the electrolyser performance running with a power input optimisation strategy. As illustrated, the electrolyser power consumption follows the electricity price variations. Therefore, in the coldest months of the year (October, November, December, January, February), when electricity prices are high, the power
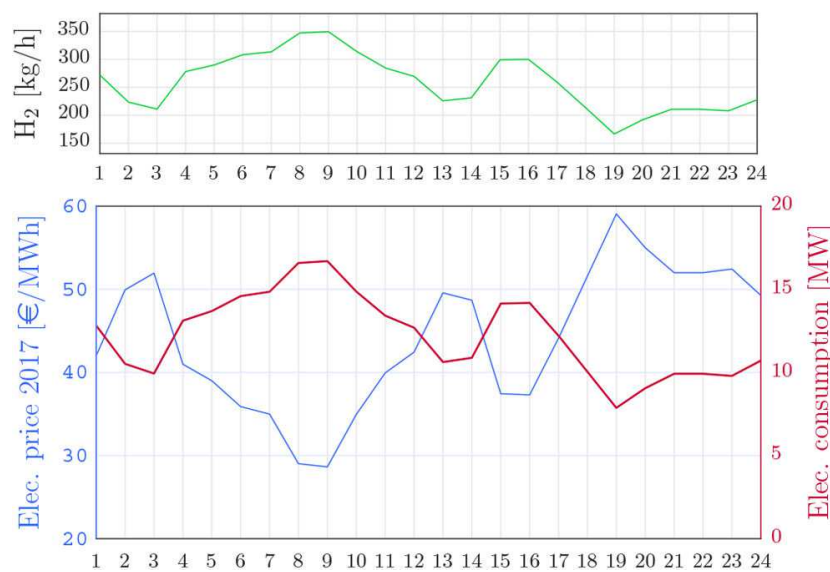

Fig. 7 Electrolyser power consumption in January

Table 4 Economic parameters for different ancillary services and operating strategies based on the optimal operating point

\begin{tabular}{lccccc}
\hline & $\begin{array}{l}\text { Power input } \\
\text { optimisation }\end{array}$ & $\begin{array}{c}100 \\
\mathrm{mHz}\end{array}$ & $\begin{array}{c}200 \\
\mathrm{mHz}\end{array}$ & $\begin{array}{c}\text { FCR } \\
\text { downwards }\end{array}$ & $\begin{array}{c}\mathrm{FCR} \\
\text { upwards }\end{array}$ \\
\hline NPV, M€ & -18.55 & 21.23 & -6.78 & -27.76 & -20.6 \\
IRR, \% & -6 & 9 & -0.7 & -13 & -7 \\
$\begin{array}{l}\text { FCR } \\
\text { income, M }\end{array}$ & - & 3.18 & 1.44 & 0.77 & 0.51 \\
$\begin{array}{l}€ \\
\mathrm{H}_{2} \text { income, }\end{array}$ & 5 & 5.3 & 5.39 & 0.97 & 6.88 \\
$\mathrm{M} €$ & & & & & \\
\hline
\end{tabular}
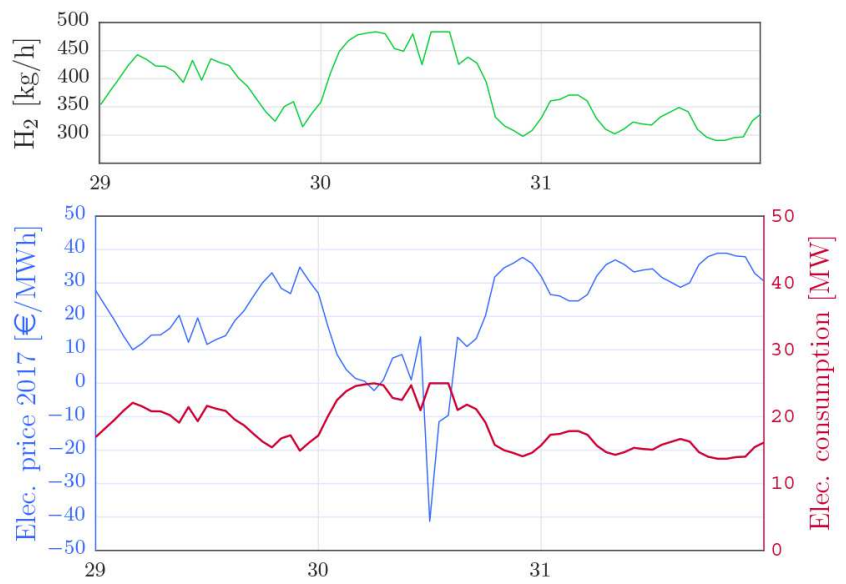

Fig. 8 Electrolyser power consumption in July

input is accordingly reduced to its minimum, and less hydrogen is produced. In contrast, in warmer months of the year, the input power and consequently the hydrogen production rise due to the low electricity price.

Figs. 6 and 7 show a detailed overview of the power consumption, electricity price, and produced hydrogen in the whole month of January and the first day of the year, respectively. As can be seen, the electrolyser power consumption is scheduled based on the electricity price. This dynamical operation of the electrolyser maximises the $\mathrm{CF}$ as the cost function is minimised As a result, despite the positive net CF, the calculated NPV is negative. The economic parameters and generated incomes from selling hydrogen are given in Table 4 .

The results show that the electrolyser is only operated at its maximum capacity on moments with a very low electricity price, particularly when the price becomes negative. As shown in Fig. 8, the electrolyser runs up to $25 \mathrm{MW}$ on the 30th of July due to the negative electricity price. 

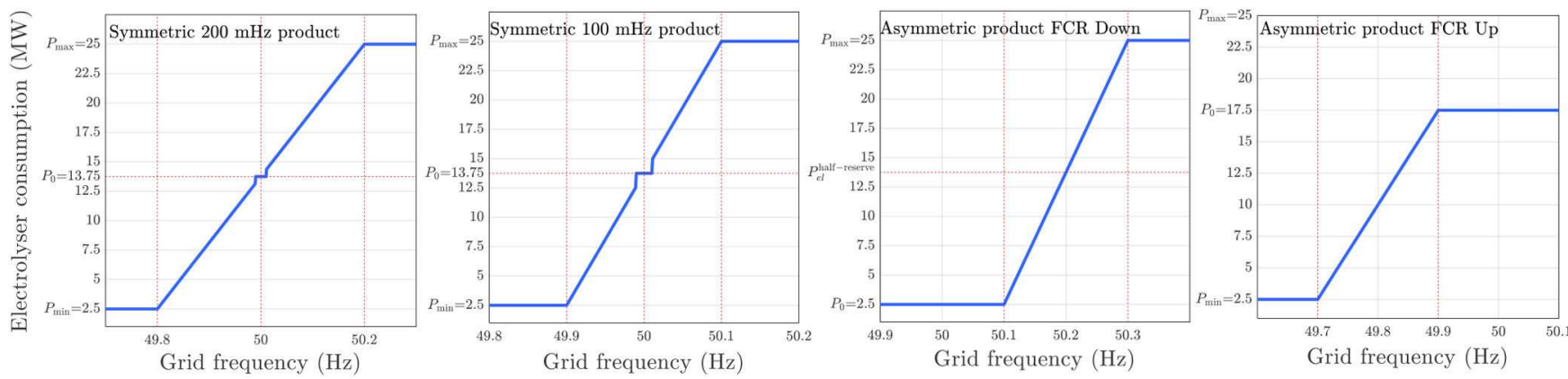

Fig. 9 Power-frequency chart in the optimal technical condition for FCR products

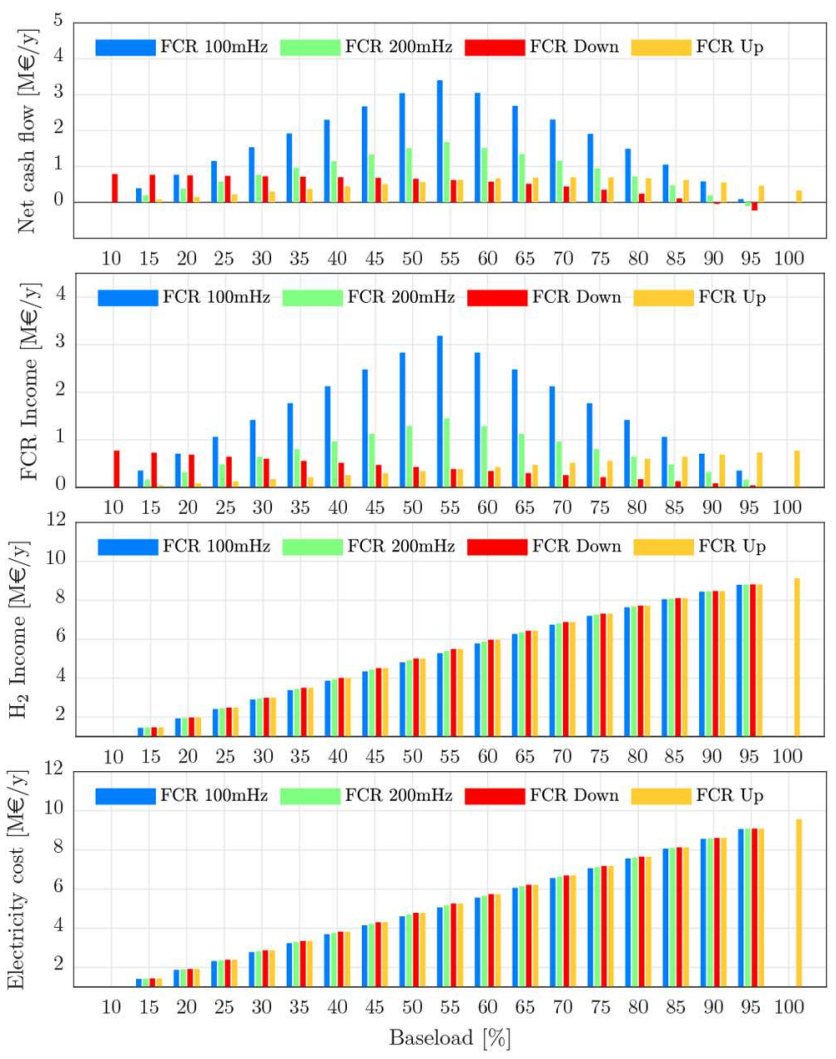

Fig. 10 Economics for the FCR products varying the baseload
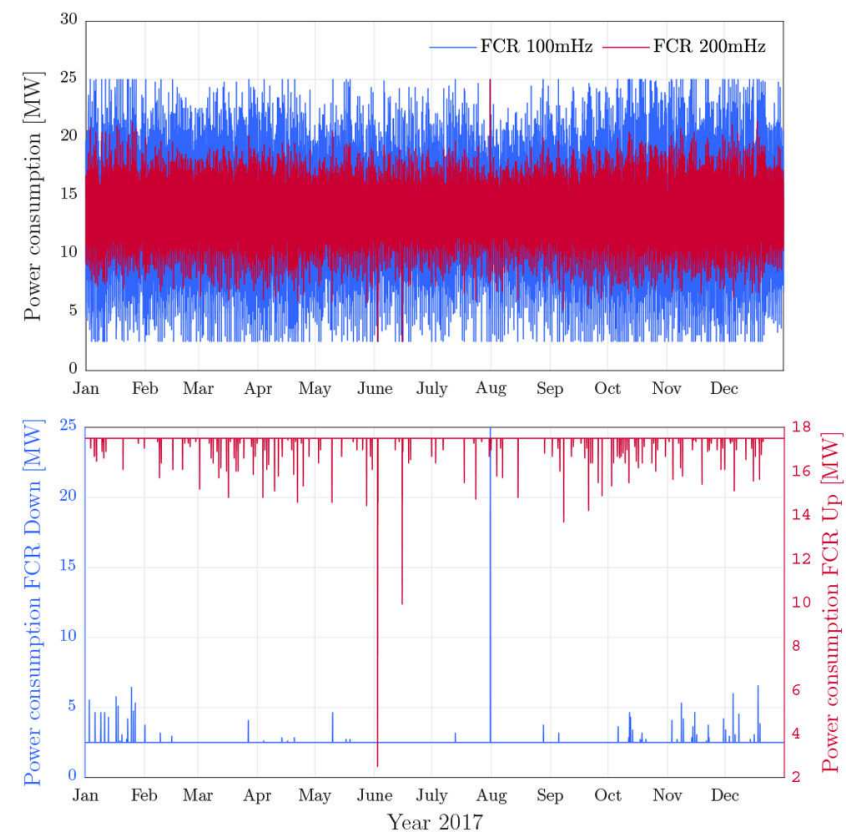

Fig. 11 Comparison of the dynamic power consumption for FCR products

\subsection{Providing primary reserve}

Fig. 9 shows the power-frequency chart of symmetric $100 \mathrm{mHz}$ product. The power input follows the frequency variation with the optimum baseload of $13.75 \mathrm{MW}$ with a reserve of $11.25 \mathrm{MW}$. However, the primary reserve does not react within the first 10 $\mathrm{mHz}$ deviations from $50 \mathrm{~Hz}$. As illustrated in Fig. 10, offering the $100 \mathrm{mHz}$ product as the primary reserve and operating the electrolyser with a baseload of $55 \%$ of its capacity, maximises the annual CF with a yearly income of $3.18 \mathrm{M} €$ by providing ancillary services. The profitability of the investment is estimated, considering a lifespan of 20 years. The power-frequency chart of symmetric $200 \mathrm{mHz}$ product is shown in Fig. 9. The maximum annual $\mathrm{CF}$ is achieved for the electrolyser operating at 55\% baseload and providing 11.25 MW power reserve (Fig. 10). As a result, running the electrolyser at its optimum baseload generates an income of 1.44 M€ from providing primary reserve and 5.39 M€ from the hydrogen production. The response of the electrolyser in function of time, delivering the symmetrical 100 and $200 \mathrm{mHz}$ products, is represented in Fig. 11. The power input variation of the electrolyser providing the $100 \mathrm{mHz}$ product is twice as high compared to the $200 \mathrm{mHz}$ product. This is because of the fact that the system reacts to the frequency deviation within a different frequency range but with the same available power reserve.

The power-frequency of the electrolyser operating at its optimum point providing the asymmetric downward product is presented in Fig. 9. The maximum net $\mathrm{CF}$ is obtained by running the electrolyser at the minimum technical capacity as baseload and providing 22.25 MW of power reserve. The optimal economic solution yields an income of $770 \mathrm{k} € /$ year from offering primary reserve and $970 \mathrm{k} € /$ year from the hydrogen sale.

Fig. 9 illustrates the power-frequency chart of the electrolyser offering the asymmetric upward product. The income of $510 \mathrm{k} € /$ year from offering primary reserve and $6.8 \mathrm{M} € /$ year from the hydrogen sale are not enough to cover the electricity cost. Therefore, the NPV becomes negative $(-20.6 \mathrm{M} € / \mathrm{MW} / \mathrm{h})$. The dynamic response of the electrolyser delivering FCR down and FCR up are shown in Fig. 11. The power input is adjusted either with increasing of frequency (FCR down) or with the frequency drop (FCR up). As shown, the electrolyser mostly operates at a very low capacity which gives rise to the poor economic viability. The optimised economic parameters and generated incomes from selling hydrogen and providing ancillary services for each ancillary product are listed in Table 4.

\subsection{Electrolyser dynamic simulation}

To test the dynamic performance of the PEM electrolyser in providing ancillary services, a cascaded control system is designed to regulate power consumption. The power reference signal reacts linearly and proportionally to the grid frequency deviation according to (6). In this control scheme, the proportional-integral (PI) controller (slow outer controller) reacts to the frequency deviation and provides the reference signal to the current controller (fast inner controller). Therefore, the cascade controller adjusts the power consumption of the electrolyser by regulating the PEM stack current. Fig. 12 illustrates the control diagram. The proportional and integral gains of the control system are given in Table 5. The output signal of the ramping block is passed to the BoP equipment 


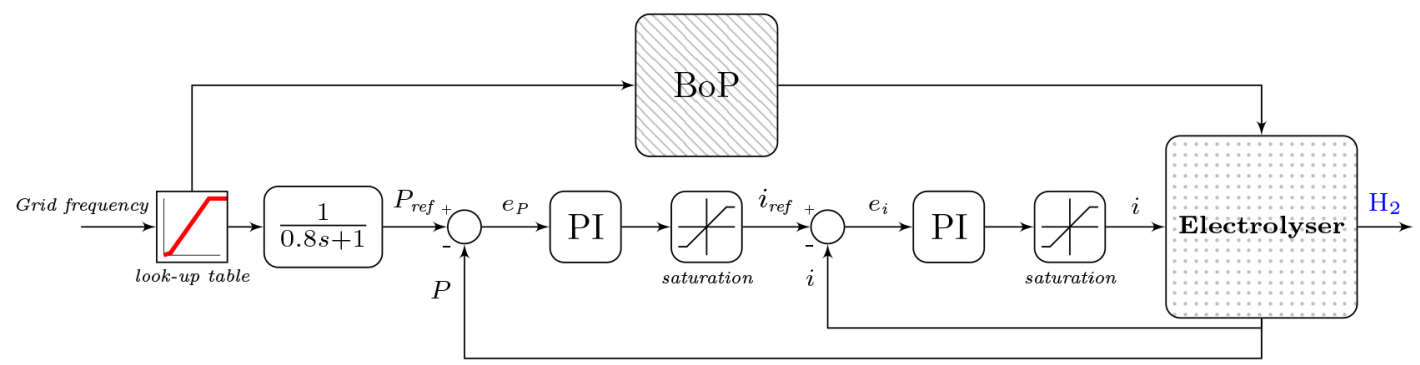

Fig. 12 Control diagram of PEM electrolyser

Table 5 Proportional and integral gains of the cascaded controller

\begin{tabular}{lcc}
\hline Controller & Proportional gain $(\mathrm{P})$ & Integral gain (I) \\
\hline power (outer loop) & 20 & 10 \\
current (inner loop) & 10 & 10 \\
\hline
\end{tabular}
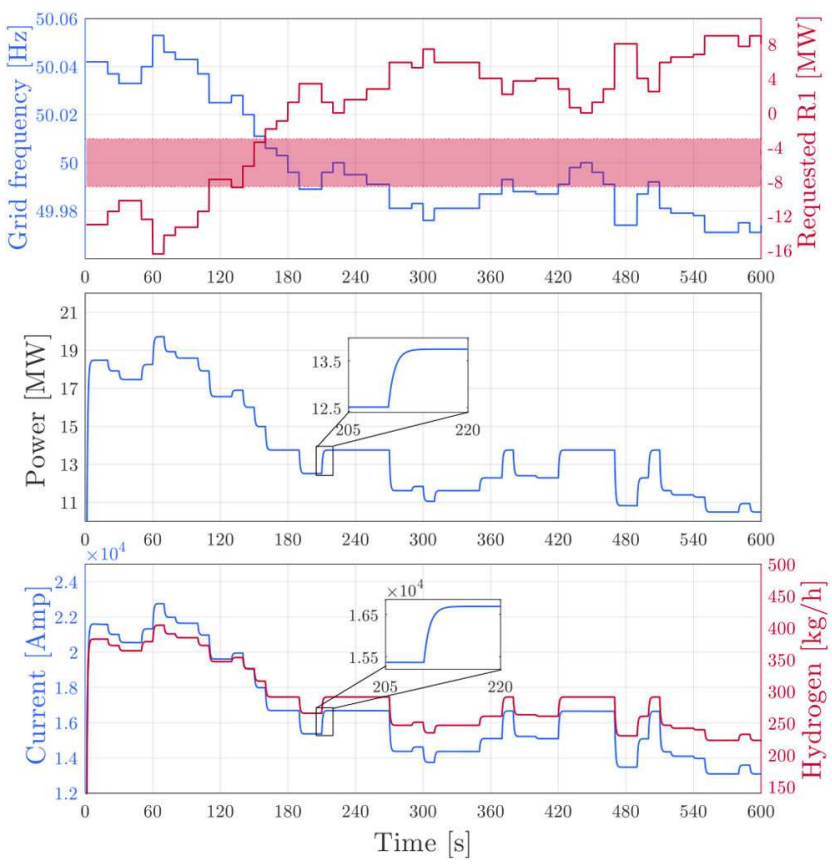

Fig. 13 Dynamics of PEM electrolyser providing FCR $100 \mathrm{mHz}$
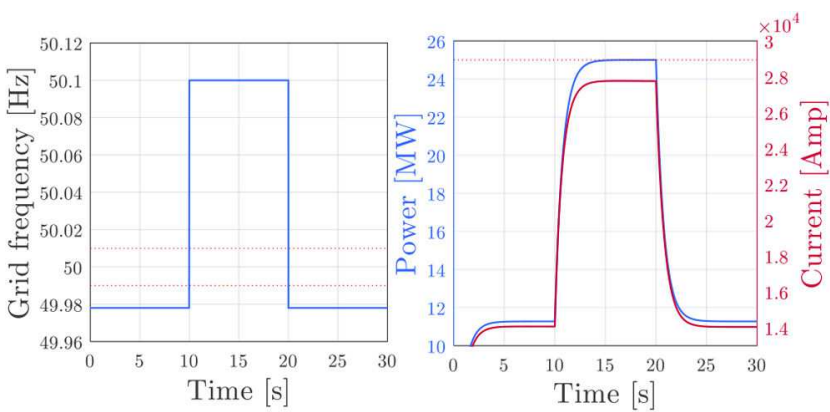

Fig. 14 Step response of PEM electrolyser to the maximum frequency variation of year 2017 occurred in Belgium

as well as the cascaded loops of the electrolyser control. Since the $\mathrm{BoP}$ reacts within $3 \mathrm{~s}$ [17], a time delay block is included in the forward path to match the responses of $\mathrm{BoP}$ and electrolyser stack.

Fig. 13 shows the flexible operation of the electrolyser providing $100 \mathrm{mHz}$ FCR. The performance of the electrolyser is monitored for $10 \mathrm{~min}$ on the first day of January 2017. The grid frequency varies every $10 \mathrm{~s}$, and the electrolysers power consumption is regulated based on the grid frequency. The $25 \mathrm{MW}$ electrolyser is operated at its optimum operating point obtained in Section 3.2. Therefore, the electrolyser operates at $55 \%$ of its full capacity while providing $11.25 \mathrm{MW}$ of the primary reserve. The power offtake is regulated with a cascade controller by regulating the current input. As illustrated in Fig. 13, the dynamics of the PEM electrolyser are considerably fast during the operation, and it can react to the grid frequency deviations within $5 \mathrm{~s}$. Therefore, the PEM electrolysis can be operated at different power values with a high degree of flexibility. Also, the hydrogen production obtained from (4) and the current input variation of the electrolyser running with the grid balancing strategy are represented in Fig. 13.

Fig. 14 demonstrates the dynamics of the 25 MW PEM electrolyser reacting to the maximal frequency deviation that occurred in the year 2017. The maximum frequency deviation is obtained for the reaction zone of FCR $100 \mathrm{mHz}(49.9-50.1 \mathrm{~Hz})$. In this frequency event, the frequency increased from 49.978 to 50.1 $\mathrm{Hz}$. The controllability of the electrolyser is tested in this region to regulate power consumption for the desired response time within a maximum of $30 \mathrm{~s}$. As shown in Fig. 14, the electrolyser responds to the $0.125 \mathrm{~Hz}$ frequency variation with an abrupt load change of 13.725 MW (11.275-25 MW and back) in $<5 \mathrm{~s}$. This shows that the PEM stack has sufficiently fast dynamic behaviour to react to realistic frequency changes and provide services to the power grid.

\section{Conclusion}

The main goal of this study is to investigate an optimal strategy for operating a large-scale electrolyser in Belgium to maximise economic efficiency by providing FCR. Therefore, we have assessed the techno-economic performance of two operational strategies for power-to-hydrogen technology. In the first strategy, the electricity consumption of the electrolyser was modulated according to the electricity price. Later, the electrolyser was operated to participate in the ancillary market, by adjusting the power offtake according to the grid frequency. Four possible ancillary service products have been investigated, and technical validation is performed for the optimal operating strategy.

The results demonstrate that operating the electrolyser to follow the electricity price would not be economically viable. This is due to the high investment cost and low hydrogen selling price. It was found that offering the symmetric primary reserve (FCR $100 \mathrm{mHz}$ ) is a valid option to generate additional revenue from ancillary services. The optimal economic strategy is to run the electrolyser at a baseload of $55 \%$ while providing the remaining capacity as a power reserve. Moreover, the Randles-Warburg electrochemical model is used to represent the dynamic behaviour of the PEM stack of the electrolyser. The electrolyser response to the maximum frequency variation has been tested to verify the controllability of the power offtake. Simulation results show that the fast dynamics of the PEM electrolyser provide a high degree of flexibility, which provides the opportunity to participate in the ancillary market.

\section{Acknowledgments}

This work was performed in the framework of the Catalisti cluster SBO project CO2PERATE ('All renewable CCU based on formic acid integrated in an industrial microgrid'), and the GREENPORTS project, with the financial support of VLAIO (Flemish Agency for Innovation and Entrepreneurship). 


\section{References}

[1] Antonelli, M., Desideri, U., Franco, A.: 'Effects of large scale penetration of renewables: the italian case in the years 2008-2015', Renew. Sustain. Energy Rev., 2018, 81, pp. 3090-3100

[2] Gerber, A., Qadrdan, M., Chaudry, M., et al.: 'A 2020 gb transmission network study using dispersed wind farm power output', Renew. Energy, 2012, 37, (1), pp. 124-132

[3] Johnson, S.C., Papageorgiou, D.J., Mallapragada, D.S., et al.: 'Evaluating rotational inertia as a component of grid reliability with high penetrations of variable renewable energy', Energy, 2019, 180, pp. 258-271

[4] Ulbig, A., Borsche, T.S., Andersson, G. 'Analyzing rotational inertia, grid topology and their role for power system stability', IFAC-PapersOnLine, 2015, 48, (30), pp. 541-547

[5] Jomaux, J., Mercier, T., De-Jaeger, E.: 'A methodology for sizing primary frequency control in function of grid inertia'. 2016 IEEE Int. Energy Conf. (ENERGYCON), Leuven, Belgium, 2016

[6] Lu, Z., Li, H., Qiao, Y.: 'Probabilistic flexibility evaluation for power system planning considering its association with renewable power curtailment', IEEE Trans. Power Syst., 2018, 33, (3), pp. 3285-3295

[7] Gao, J., Ma, Z., Guo, F. 'The influence of demand response on windintegrated power system considering participation of the demand side', Energy, 2019, 178, pp. 723-738

[8] Gür, T.M.: 'Review of electrical energy storage technologies, materials and systems: challenges and prospects for large-scale grid storage', Energy Environ. Sci., 2018, 11, (10), pp. 2696-2767

[9] Huang, Y., Keatley, P., Chen, H., et al.: 'Techno-economic study of compressed air energy storage systems for the grid integration of wind power', Int. J. Energy Res., 2018, 42, (2), pp. 559-569

[10] Zhao, H., Hong, M., Lin, W., et al.: 'Voltage and frequency regulation of microgrid with battery energy storage systems', IEEE Trans. Smart Grid, 2019, 10, (1), pp. 414-424

[11] Zhang, Y., Campana, P.E., Lundblad, A., et al.: 'Comparative study of hydrogen storage and battery storage in grid connected photovoltaic system: storage sizing and rule-based operation', Appl. Energy, 2017, 201, pp. 397411

[12] Melo, D.F.R., Chang-Chien, L.R.: 'Synergistic control between hydrogen storage system and offshore wind farm for grid operation', IEEE Trans. Sustain. Energy, 2013, 5, (1), pp. 18-27

[13] Díaz-González, F., Sumper, A., Gomis-Bellmunt, O., et al: 'A review of energy storage technologies for wind power applications', Renew. Sustain. Energy Rev., 2012, 16, (4), pp. 2154-2171

[14] Navas-Anguita, Z., García-Gusano, D., Dufour, J., et al.: 'Prospective technoeconomic and environmental assessment of a national hydrogen production mix for road transport', Appl. Energy, 2020, 259, p. 114121

[15] Lux, B., Pfluger, B.: 'A supply curve of electricity-based hydrogen in a decarbonized european energy system in 2050', Appl. Energy, 2020, 269, p. 115011

[16] Tuinema, B.W., Adabi, E., Ayivor, PK et al. 'Modelling of large-sized electrolysers for real-time simulation and study of the possibility of frequency support by electrolysers', IET. Gener. Transm. Distrib., 2020, 14, (10), pp. 1985-1992

[17] Mohanpurkar, M., Luo, Y., Terlip, D., et al.: 'Electrolyzers enhancing flexibility in electric grids', Energies, 2017, 10, (11), p. 1836

[18] Allidières, L., Brisse, A., Millet, P., et al.: 'On the ability of pem water electrolysers to provide power grid services', Int. J. Hydrog. Energy, 2019, 44, (20), pp. 9690-9700
[19] Matute, G., Yusta, J., Correas, L.: 'Techno-economic modelling of water electrolysers in the range of several $\mathrm{mw}$ to provide grid services while generating hydrogen for different applications: a case study in spain applied to mobility with fcevs', Int. J. Hydrog. Energy, 2019, 44, (33), pp. 17431-17442

[20] Thomas, D., Mertens, D., Meeus, M., et al.: 'Power-to-gas roadmap for flanders', WaterstofNet vzw, 2016

[21] Kiaee, M., Cruden, A., Infield, D., et al.: 'Utilisation of alkaline electrolysers to improve power system frequency stability with a high penetration of wind power', IET Renew. Power Gener, 2013, 8, (5), pp. 529-536

[22] Liso, V., Savoia, G., Araya, S., et al.: 'Modelling and experimental analysis of a polymer electrolyte membrane water electrolysis cell at different operating temperatures', Energies, 2018, 11, (12), p. 3273

[23] Zhang, H., Su, S., Lin, G., et al: 'Efficiency calculationand configuration design of a pem electrolyzer system for hydrogen production', Int. J. Electrochem. Sci., 2012, 7, pp. 4143-4157

[24] Atlam, O., Kolhe, M.: 'Equivalent electrical model for a proton exchange membrane (pem) electrolyser', Energy Convers. Manage., 2011, 52, (8), pp. 2952-2957

[25] Yigit, T., Selamet, O.F.: 'Mathematical modeling and dynamic simulink simulation of high-pressure pem electrolyzer system', Int. J. Hydrog. Energy, 2016, 41, (32), pp. 13901-13914

[26] Dale, N.V., Mann, M.D. Salehfar, H. 'Semiempirical model based on thermodynamic principles for determining $6 \mathrm{kw}$ proton exchange membrane electrolyzer stack characteristics', J. Power Sources, 2008, 185, (2), pp. 1348-1353

[27] Awasthi, A., Scott, K., Basu, S.: 'Dynamic modeling and simulation of a proton exchange membrane electrolyzer for hydrogen production', Int. $J$. Hydrog. Energy, 2011, 36, (22), pp. 14779-14786. fuel Cell Technologies: FUCETECH 2009

[28] Bertuccioli, L., Chan, A., Hart, D., et al.: 'Study on development of water electrolysis in the eu', Fuel Cells Hydrogen Joint Undertaking, 2014

[29] Guilbert, D., Vitale, G.: 'Dynamic emulation of a pem electrolyzer by time constant based exponential model', Energies, 2019, 12, (4), p. 750

[30] Garcia-Navarro, J.C., Schulze, M., Friedrich, K.A.: 'Measuring and modeling mass transport losses in proton exchange membrane water electrolyzers using electrochemical impedance spectroscopy', J. Power Sources, 2019, 431, pp. 189-204

[31] Saadi, A., Becherif, M., Hissel, D., et al.: 'Dynamic modeling and experimental analysis of pemfcs: a comparative study', Int. J. Hydrog. Energy, 2017, 42, (2), pp. 1544-1557

[32] Rubio, M., Urquia, A., Dormido, S: 'Diagnosis of pem fuel cells through current interruption', J. Power Sources, 2007, 171, (2), pp. 670-677

[33] Martinson, C., Van-Schoor, G., Uren, K., et al.: 'Equivalent electrical circuit modelling of a proton exchange membrane electrolyser based on curren interruption'. 2013 IEEE Int. Conf. on Industrial Technology (ICIT). (IEEE), Cape Town, South Africa, 2013, pp. 716-721

[34] Darowicki, K., Gawel, L.: 'Impedance measurement and selection of electrochemical equivalent circuit of a working pem fuel cell cathode', Electrocatalysis, 2017, 8, (3), pp. 235-244

[35] Martinson, C.A., Van-Schoor, G., Uren, K et al. "Characterisation of a pem electrolyser using the current interrupt method', Int. J. Hydrog. Energy, 2014, 39, (36), pp. 20865-20878 